\title{
MODELO DE PREVISÃO DE DEMANDA PARA ATMS UTILIZANDO REDE NEURAL ARTIFICIAL DO TIPO MULTLAYER PERCEPTRON
}

\section{DEMAND FORECASTING MODEL FOR ATMS USING MULTILAYER PERCEPTRON ARTIFICIAL NEURAL NETWORK}

Marcos Vieira da Silva, Ana Carolina Nicolosi da Rocha Gracioso

Faculdade de Tecnologia do Estado de São Paulo - FATEC, Presidente Prudente, SP. E-mail: marcos@maximize-tic.com.br

RESUMO - A previsão de reposição de numerários para Automated Teller Machine (ATM) - caixa eletrônico para autoatendimento bancário - fornece a uma rede bancária otimização e maior eficiência em todo processo de reabastecimento de valores em ATMs, por consequência propiciando segurança, redução de custos e equilíbrio em relação às sazonalidades. Objetivo deste trabalho foi elaborar uma Rede Neural Artificial (RNA) para estimar os valores diários de saques considerando também outras variáveis que pudessem influenciar na sazonalidade dessas movimentações. A Rede Neural Artificial, do tipo FeedForward Multilayer Perceptron (MLP), foi treinada tomando-se por referência dados de movimentação de ATMs de diferentes pontos de localização. Nas camadas intermediárias e de saída foram utilizadas funções de ativação do tipo relu-adam. Assim, o desempenho da RNA desenvolvida se mostrou satisfatório, podendo ser considerada como modelo para implementação de uso efetivo na operação de reposição de numerários de caixas eletrônicos de autoatendimento em redes bancárias ou de pontos compartilhados de autoatendimento.

Palavras-chave: Redes Neurais Artificias; Multilayer Perceptron; Reposição de Numerários de ATMs; Previsão de Reabastecimento de ATMs.

ABSTRACT - The projections of replacement of cash for Automated Teller Machine (ATM) ATM for bank self-service provides to a banking network optimization and greater efficiency in all process of replacement of values in ATMs, as a result providing security, cost reduction, and balance in relation to seasonality. The aim of this work was to develop an Artificial Neural Network (ANN) to estimate the daily withdrawal values, also considering other variables that could influence the seasonality of these movements. The Artificial Neural Network, of the FeedForward Multilayer Perceptron (MLP) type, was trained based on ATM movement data from different location points. In the intermediate and output layers, activation functions of the relu-adam type were used. Thus, the performance of the developed ANN proved to be satisfactory, and it can be considered as a model for the implementation of effective use in the operation of cash replacement in ATMs of the bank networks or in shared ATMs.

Keywords: Artificial Neural Networks; Multilayer Perceptron; ATM Cash Replenishment; ATM Refueling Projections. 
1.

\section{INTRODUÇÃO}

O gerenciamento eficiente dos Automated Teller Machine's (ATMs) podem reduzir os custos financeiros devido ao estoque armazenado não utilizado de numerários. Prever a demanda por caixa é desafiador por causa da imprevisibilidade de saques, mas lucrativo por causa do grande número de máquinas. Mais de 3,2 milhões de caixas eletrônicos são usados em todo o mundo e estima-se chegar a 4 milhões até 2021. Por meio da otimização do gerenciamento de estoque de numerários, instituições financeiras podem evitar a superestimação das quantidades de valores para cada ponto a ser abastecido e melhorar os lucros mobilizando capital ocioso em outras operações bancárias como empréstimos e financiamentos por exemplo. Evita também a subestimação, que por sua vez, pode causar a falta de valores para atender a demanda causando desconfortos aos clientes e usuários entre outros problemas decorrentes. Outro problema que pode ser reduzido com a otimização dos valores de reposição são as perdas referentes a roubos de ATMs, pressupondo que ao manter os estoques de numerários justos baseado no histórico de movimentação de cada ATM as perdas podem ser consideravelmente reduzidas na inevitabilidade de tais ocorrências. Situações extremamente atípicas e imprevisíveis como o período de quarentena em decorrência do surto mundial de coronavírus (SARS-CoV-2) causador da Covid-19, iniciada no primeiro trimestre de 2020, também impactam sensivelmente todo processo. $\mathrm{O}$ uso do distanciamento social como controle da proliferação do vírus e o fechamento de indústrias, comércios e serviços considerados não essenciais reduziram as movimentações de saques consideravelmente. Em contrapartida houve crescimento nas operações digitais, desse modo, um redirecionamento dos recursos de abastecimento dos ATMs dispondo de numerários adequados ao novo cenário promoveria as mesmas vantagens e otimizações em cenários normais. Portanto, é crucial métodos avançados para prever com precisão a demanda de numerários para cada caixa eletrônico. Um sistema inteligente de gerenciamento para previsão de demanda de caixa pode ajudar os bancos a reduzir os custos operacionais e melhorar o retorno de seus ativos em dinheiro. Portanto este estudo busca simular a aplicação de uma Rede Neural Artificial do tipo FeedForward Multilayer Perceptron, para estimar os valores diários de saques com objetivo de alcançar um modelo de predição que possa ser utilizado para estimar a reposição de numerários e ou que possa ser retreinado com base em registros de movimentações recentes, considerando situações atípicas realizando previsões de acordo com novos cenários.

\section{FUNDAMENTAÇÃO TEÓRICA}

Esta seção visa discutir alguns trabalhos com os mesmos objetivos deste estudo.

\subsection{Estado da Arte}

O trabalho proposto por Gedson Santos de Melo aplica dois diferentes métodos para realizar a previsão. O primeiro baseado na rede neural artificial Long short-term memory (LSTM) que obteve um erro percentual absoluto (MAPE) de $36,231 \%-18,110 \%$. E o segundo que utilizou a rede neural artificial Multilayer Perceptron (MLP) com algoritmo backpropagation que obteve um MAPE de 33,386\% - 18,808\%, ambas em situações de múltiplos passos. Os percentuais de erros foram obtidos com dados de ATMs do City Union Bank da Índia obtidos no site de competição de ciência de dados chamado Kaggle especificamente sobre as movimentações do ATM Airport e ATM Big Street, respectivamente nessa ordem. O estudo realizado por Pavel Leonov, Artyom Sviridenko, Elizaveta Leonova, Michael Epifanov e Ekaterina Nikiforova, sugere a aplicação de uma Convolutional Neural Network (CNN) para analisar o fluxo de caixa de ATMs com as funções de depósitos e saques de dinheiro em moeda local (Rublos) com base em registros no período entre os meses de Fevereiro a Setembro de 2018. O modelo CNN com duas camadas apresentou o melhor resultado com 0,91 de acurácia. O modelo de uma camada resultou em uma acurácia de 0,74.

Nidhi Arora e Jatinder Kumar, sugere a aplicação da Rede Neural fuzzy ARTMAP obtendo como resultados uma acurácia de $96.05 \%$ e 97.2\% considerando variações dos erros em função de mudanças de parâmetros e tamanho do dataset. Para esse experimento foi utilizado dados históricos de movimentação de ATMs de um período de 2 anos, o nome do banco não foi mencionado com base em sua solicitação para manter a confidencialidade. 


\subsection{Previsão de Demanda}

Sobre a previsão de demanda e sua relação com gerenciamento de recursos e tomada de decisão estratégica, é afirmativo que:

Chama-se de demanda a disposição de um mercado ao consumo de produtos e serviços. Dessa forma, prever a demanda pode ser extremamente

importante para o planejamento e para a tomada de decisões. Utiliza-se a previsão de demanda, por exemplo, para o projeto de um sistema produtivo ou para o planejamento e programação da produção.

Assim, a previsão tem o objetivo de fornecer informações sobre a demanda futura para antecipar suas variações e suas consequências, possibilitando um planejamento que forneça melhores resultados. (PAIVA, 2006, p. 23).

Portanto, a previsão de demanda trata-se de uma estimativa do que irá ocorrer a partir da mensuração de um determinado período futuro, sobre que tende a influenciar um processo produtivo. A partir desta previsão é possível ter informações para embasar tomadas de decisões e precaver-se de fatores e sazonalidades que possam afetar todo processo dentro do período determinado.

\subsection{Aprendizado de Máquina}

$\mathrm{O}$ aprendizado de máquina ou machine learning é o termo que define um campo de estudos que busca simular através de algoritmos a capacidade natural humana de "aprender com a experiência" e prover a capacidade de computadores aprenderem a analisar dados e identificar padrões. É um campo de estudos da Ciência da Computação sendo subárea da Inteligência Artificial.

De acordo com Melo (2018, p. 4) "Há muitas razões para afirmar que aprendizado de máquina é importante. Pode-se citar que a realização de aprendizado em máquinas ajuda no entendimento de como os animais e humanos aprendem. Mas há razões importantes na engenharia também".

Caracteristicamente os algoritmos de aprendizado de máquina tem a capacidade de aprender por meio de exemplos. Existe um grande número de algoritmos classificados em diferentes categorias, tais como: aprendizagem supervisionada, aprendizagem nãosupervisionada, aprendizagem semisupervisionada e aprendizagem por reforço. Para este estudo utilizou-se a aprendizagem supervisionada, cujo os principais algoritmos dessa categoria são: Árvores de Decisão, Classificação Naïve Bayes, Regressão Linear de Mínimos Quadrados, Regressão logística, Support Vector Machine, Ensemble Methods, Algoritmos de Agrupamento (Clustering), entre outros.

Alguns desses algoritmos fazem parte de uma outra subdivisão classificada como redes neurais artificiais (RNA). Neste estudo iremos tratar da RNA Multilayer Perceptron (MLP).

\subsection{Redes Neurais Artificiais}

Redes Neurais Artificiais são sistemas paralelos distribuídos compostos por unidades de processamento simples identificados como nós ou neurônios capazes de calcular funções matemáticas não-lineares, distribuídas em uma ou mais camadas e interligadas por um grande número de conexões. Em grande parte dos modelos essas conexões são associadas a pesos que guardam o conhecimento adquirido pelo modelo para ponderar as entradas recebidas por cada neurônio de suas camadas antecessoras em uma rede (BRAGA; CARVALHO; LUDERMINR,et al., 2007, p. 74).

De acordo com Braga, Carvalho e Luderminr (2007, p. 6) "AS RNAs tentam reproduzir as funções das redes biológicas, buscando implementar seu comportamento funcional e sua dinâmica". Representação de um modelo simplificado, na Figura 1, de um modelo de um neurônio biológico e um neurônio matemático. 
Figura 1. Neurônio biológico vs. Neurônico Matemático

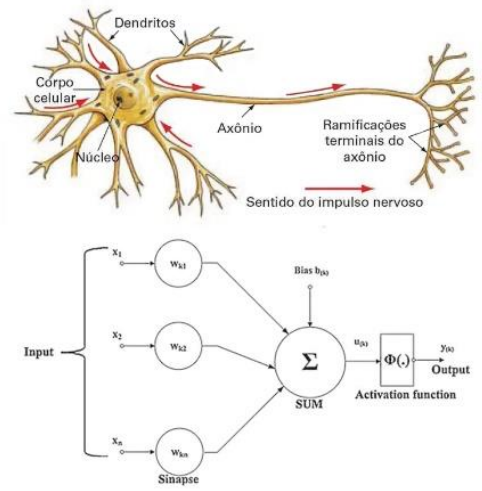

Fonte: Adaptado de Deep Learning Book (2020).

\subsection{Multlayer Perceptron}

Segundo Shah e Ghazali (2011 apud Coutinho et al. 2016, p. 26.) "A RNA do tipo Multilayer Perceptron (MLP) pertence à classe de RNAs conhecida como feedforward, além de ser uma aproximadora universal de funções, que tem sido aplicada em diferentes problemas combinatórios e na solução de diferentes tarefas como processamento de informações, reconhecimento de padrões, previsões do tempo, problemas de classificação, processamento de imagens, previsões de atividades sísmicas e outros".

Figura 2. Arquitetura RNA Perceptron Simples

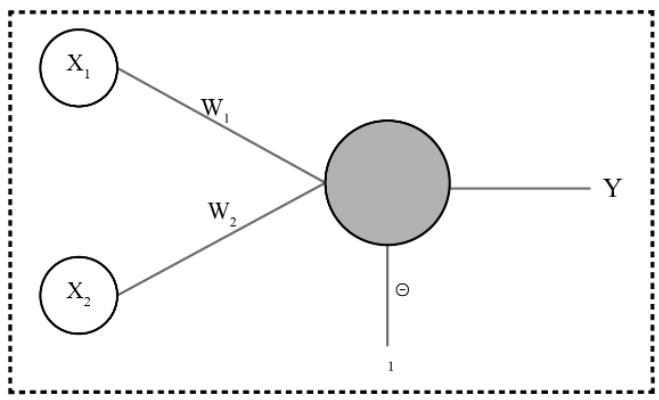

Fonte: Adaptado de MELO (2018)

Segundo Coutinho (2016, p.26) "A estrutura de uma MLP é formada por um conjunto de neurônios dispostos em camadas, contendo uma camada de entrada, uma ou mais camadas intermediárias, e uma camada de saída. Cada um dos neurônios da camada de entrada está conectado a todos os neurônios da camada intermediária. Da mesma forma, cada neurônio da camada intermediária está conectado com todos os neurônios da camada de saída" (apud Hall et al., 1999; Asaduzzaman et al., 2010).

Para solução de problemas de maior complexidade, não linearmente separáveis, uma
MLP simples (vide Figura 2) é incapaz de resolver, - que limita sua aplicação fazendo assim necessário a adoção do algoritmo de treinamento backpropagation para solução deste problema.

Segundo Melo (2018, p. 5) "Uma MLP back-propagation contém uma ou mais camadas ocultas, além de uma entrada e uma camada de saída".

Figura 3. Rede MLP com duas camadas intermediárias.

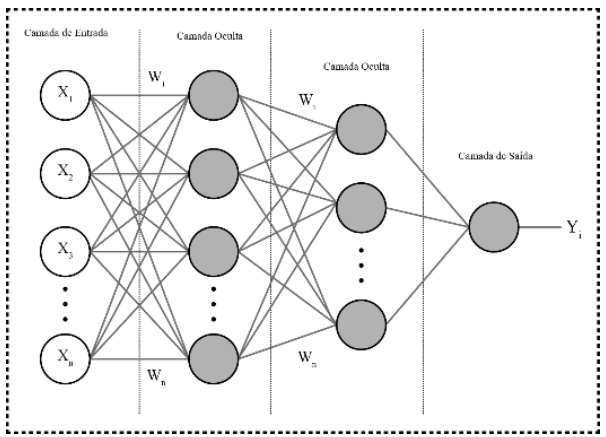

Fonte: Adaptado pelo autor

A camada de entrada da Figura 3 possui os nós (X1...Xn) como entrada dos dados, valores numéricos dependentes do conjunto de dados. Nenhum cálculo é realizado na camada de entrada, portanto seus valores inalterados são inseridos na camada oculta. A primeira camada intermediária da Figura 3, possui a mesma quantidade de nós da camada de entrada (X1...Xn) e sua saída depende das saídas da camada de entrada bem como a saída dos pesos (Wi...Wn) associados às arestas (conexões), que são iniciados com valores iniciais aleatórios, na equação (1) está representado este cálculo. Cada nó (neurônio) da segunda camada oculta da Figura 3 combina os valores descritos pela camada anterior conectados a ele e executa cálculos semelhantes. A camada de saída da Figura 3 recebe os valores da última camada oculta anterior e o resultado dos valores calculados (Yi) atua como resultado da MLP.

$$
\text { soma }=\sum_{i=1}^{n} x i * w i
$$

"Dado um conjunto de características $X=$ $(X 1, X 2 \ldots X n)$ e um alvo $Y$, uma MLP pode aprender a relação entre os recursos e o alvo, tanto para classificação quanto para regressão" (MELO, 2018, p. 6).

"O algoritmo backpropagation ou algoritmo de retro propagação de erros é uma técnica de treinamento supervisionado que 
realiza o ajuste dos pesos através do cálculo da diferença entre o valor predito pela rede e o valor esperado" (COUTINHO, 2018, p.27). O treinamento ocorre em duas fases distintas: a fase forward utilizada para definir a saída para um dado padrão de entrada, e a fase backward que utiliza a diferença entre a saída desejada e a saída obtida para atualizar os pesos de suas conexões (BRAGA; CARVALHO; LUDERMINR, 2007, p. 74). A Figura 4 ilustra essas duas fases.

Figura 4. Fases forward e backward

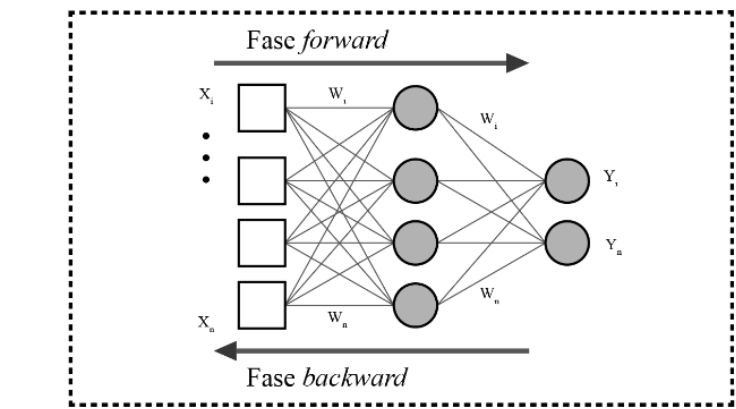

Fonte: Adaptado pelo autor

Para o objetivo deste estudo que é a previsão de reposição de numerários para ATMs será aplicado o aprendizado supervisionado utilizando a RNA Feedforward Multilayer Perceptron com algoritmo backpropagation. As etapas do processo de implementação são explicadas em detalhes nas seções subsequentes.

\section{MATERIAIS E MÉTODOS}

\subsection{Dados utilizados}

O conjunto de dados utilizados pode ser encontrado para download em um website que promove competições de ciência de dados e machine learning (aprendizado de máquina) chamado Kaggle. O dataset $^{1}$ possui 11.589 registros de informações de movimentações de ATMs do "Data of ATM transaction of XYZ bank" compreendendo o período de 01/01/2011 a 29/09/2017. A base de dados (dataset) utilizada neste trabalho contém as seguintes informações: ATM Name, Transaction Date, No. Of Withdrawals, No Of XYZ Card Withdrawals, No Of Other Card Withdrawals, Total amount Withdrawn, Amount withdrawn XYZ Card, Amount withdrawn Other Card, Weekday, Festival Religion, Working Day, Holiday Sequence.

\footnotetext{
${ }^{1}$ Kaggle, Data of ATM transactions of XYZ bank, 2019
}

\subsection{Análise Exploratória dos Dados}

Em geral a AED - Análise Exploratória de Dados, é uma abordagem estatística de avaliação gráfica sobre o conjunto de dados e suas principais características. É uma etapa que antecede a construção do modelo, pois os resultados obtidos podem ser úteis para guiar a construção do modelo a ser aplicado no problema, simplificando o conjunto de hipóteses, reduzindo a dimensão do conjunto de dados e tornando o problema menos complexo e economizando o tempo de treinamento do modelo, por consequência reduzindo o custo computacional do problema.

Para compreender o comportamento da variável a ser predita foram selecionados os dados do Total de Valores Sacados (Total amount Withdrawn) no intervalo de movimentações de 2013 a 2017 de todos ATMs como parâmetros e gerado um gráfico em linha utilizando o método (pyplot) da biblioteca matplotlib e comparando os valores absolutos em relação à média ao longo dos anos. Os resultados podem ser observados na seção 4.1.

Com objetivo de observar a distribuição e a frequência dos valores da variável a ser predita foi gerado um histograma utilizando do método (distplot) da biblioteca de visualização de dados seaborn usando como parâmetro os dados do Total de Valores Sacados (Total amount Withdrawn). Os histogramas agregam dados numéricos em grupos de intervalos idênticos, denominados bins e exibem a frequência de valores dentro de cada bin, para determinar o número de bins para o histograma foi utilizada o número de itens da raiz quadrada dos dados do Total de Valores Sacados através do método (sqrt) da biblioteca matemática numpy que retorna uma raiz quadrada não-negativa de um array e da função (len) que retorna um número de itens de um objeto. Os resultados podem ser observados na seção 4.1.

Para observar se haveria ou não existência de correlação entre as variáveis e qual a intensidade dessa relação das movimentações dos ATMs listados na base de dados, foi gerado um gráfico (ou diagrama) de dispersão através do método (scatterplot) da biblioteca de visualização de dados seaborn, utilizando como parâmetros dos dados do No. Of Withdrawals (número de saques) e o Total amount Withdrawn (total sacado) considerando cada ATM (ATM Name) como referência para observação. Os resultados podem ser observados na seção 4.1. 
Para preparação e seleção dos dados para serem usados na RNA deste estudo, a AED será considerada na seleção e pré-processamento das variáveis independentes, explicadas com mais detalhes nas seções seguintes.

\subsection{Pré-Processamento dos dados}

Foram selecionadas apenas as seguintes informações da base de dados como foco para aplicação deste estudo: ATM Name, Transaction Date, No. Of Withdrawals, Weekday, Festival Religion, Working Day, Holiday Sequence, como as variáveis peditoras, ou de entrada e a Total amount Withdrawn sendo a variável de resposta (a ser predita) ou de saída.

Os dados categóricos, ou variáveis dummy, tais como: ATM Name, Weekday, Festival Religion, Working Day, Holiday Sequence, para serem utilizados na RNA foram transformados em numéricos através da técnica One-Hot Econding, que torna binário os dados onde o número 1 representa o valor afirmativo e o 0 negativo melhorando a leitura do modelo de predição, especialmente em modelos de regressão.

Os dados da variável Transaction Date foram separados em colunas distintas para Day, Month, Year, tornando-as assim variáveis de entradas independentes, conforme apresentado na Tabela 1.

Tabela 1. Amostra do dataset.

\begin{tabular}{cc}
\hline Indice & Transtion Date \\
\hline $\mathbf{0}$ & $2011-01-01$ \\
\hline $\mathbf{1}$ & $2011-01-01$ \\
\hline $\mathbf{2}$ & $2011-01-01$ \\
\hline
\end{tabular}

Os dados alteados após as alterações da seção anterior podem ser observados na Tabela 2.

Tabela 2. Amostra do dataset quando aplicada alteração

\begin{tabular}{cccc}
\hline Indice & Day & Month & Year \\
\hline 0 & 1 & 1 & 2011 \\
\hline 1 & 1 & 1 & 2011 \\
\hline 2 & 1 & 1 & 2011 \\
\hline
\end{tabular}

\subsection{Normalização dos dados}

O processo de normalização dos dados de entrada implica em uma melhor e mais rápida convergência para o algoritmo de aprendizado de máquina. $\mathrm{O}$ objetivo da normalização é garantir uma uniformidade dos dados, que podem se apresentar muito discrepantes em uma série temporal (vide Figura 5), portanto facilitando seu processo para o alcance do ponto ótimo. $\mathrm{Na}$ Tabela 3 podemos observar os dados no estado padrão do dataset.

Tabela 3. Amostra do dataset.

\begin{tabular}{ccc}
\hline Indices & $\begin{array}{c}\text { No Of } \\
\text { Withdrawls }\end{array}$ & $\begin{array}{c}\text { Total amount } \\
\text { Withdrawn }\end{array}$ \\
\hline 0 & 50 & 123800 \\
\hline 1 & 253 & 767900 \\
\hline 2 & 98 & 503400 \\
\hline
\end{tabular}

Com objetivo de garantir uma predição de maior acurácia foi utilizado para esse processo - StandarScaler, que transforma os dados de tal maneira que sua distribuição terá um valor médio 0 e um desvio padrão 1. Dada a distribuição dos dados, cada valor no conjunto de dados terá o valor médio subtraído e, em seguida, dividido entre o desvio padrão de todo o conjunto de dados.

Os dados normalizados após esse processamento podem ser observados na Tabela 4.

Tabela 4. Amostrara do dataset após normalização dos dados.

\begin{tabular}{ccc}
\hline Indices & $\begin{array}{c}\text { No Of } \\
\text { Withdrawls }\end{array}$ & $\begin{array}{c}\text { Total amount } \\
\text { Withdrawn }\end{array}$ \\
\hline 0 & -1.089563 & -1.226917 \\
\hline 1 & 1.926227 & 0.756133 \\
\hline 2 & -0.376470 & -0.058207 \\
\hline
\end{tabular}

\subsection{Codificação do algoritmo}

O desenvolvimento da RNA para de previsão de demanda para ATMs foi realizado utilizando a linguagem de programação Python (3.6.7) com auxílio da plataforma Colaboratory Google Research - Google (C). Foi utilizando no algoritmo desenvolvido a biblioteca scikit-learn (v0.23.1), uma robusta biblioteca open source de aprendizado de máquina que provê um pacote amplo e eficiente de recursos e algoritmos de classificação, regressão, avaliação entre outros. A definição da biblioteca para desenvolvimento do algoritmo foi baseada em sua facilidade de uso, ampla utilização em diferentes aplicações e uma completa documentação e atualizações constantes. Considerando os dados já préprocessados e normalizados através dos métodos aplicados anteriormente, deve-se realizar os 
processos de separação dos conjuntos de teste e conjunto de treinamento subdivididos em conjuntos de entrada (X) e saída (Y), e em seguida, a configuração e treinamento da RNA. Para a separação dos determinados conjuntos foi utilizada a classe (train_test_split) da biblioteca scikit-learn utilizando os parâmetros (test_size $=0.20$ ) para determinar que $20 \%$ do dataset será usado no conjunto de testes $(80 \%$ restantes no conjunto de treinamento), parâmetro (random_state $=42$ ) responsável por garantir o equilíbrio de distribuição e aleatoriedade das amostras de dados para cada conjunto e o parâmetro (batch_size $=1$ ) que define o número de amostras que serão propagadas pela rede a cada época de treinamento. Para exemplificar esse parâmetro digamos que se tenha 1 bilhão de dados de treinamento, se o valor do (bacth_size) fosse igual a 512, o algoritmo obteria em cada época 512 dados de treinamento para processar. Portanto, o tamanho do (bacth_size) define a quantidade de dados que você deseja processar em cada época, essa configuração levaria aproximadamente 1.953 .125 épocas para ser concluída (1.000.000.000 / 512).

Para configuração e treinamento da RNA será utilizado o objeto MLPRegressor disponível na biblioteca scikit-learn, que detém as implementações necessárias para a RNA e do algoritmo backpropagation. Para este estudo, instanciado o objeto, foram utilizados os seguintes parâmetros: (activation), responsável por determinar a função de ativação das camadas ocultas, (solver) responsável pela otimização dos pesos, (max_iter) responsável pela definição de um limite máximo de iterações por camada analisada e o (hidden_layer_sizes) responsável por determinar a quantidade de neurônios por camada utilizada. A determinação dos valores a serem utilizados foram baseados em diversos testes, aferindo a eficácia dos resultados de acordo com os parâmetros definidos. Para execução do treinamento da RNA foi utilizado o método (.fit) da classe MLPRegressor informando como parâmetro os conjuntos de treinamento de entrada e saída. Para realização da predição dos dados, foi utilizado o método (.predict) também disponível através do objeto MLPRegressor informando como parâmetro os dados de entrada do conjunto de testes. Esse método retorna os valores estimados pelo algoritmo baseado em seu aprendizado na etapa de treinamento. Para este estudo os resultados esperados são valores mais próximos possíveis do total de saques diários reais para cada ATM.

\subsection{Métodos para análise \\ Mean Square Absolute Error (MAPE)}

Erro Percentual Absoluto Médio (MAPE)

calcula o percentual médio sobre o desvio absoluto entre o real e o previsto. Devido a sua fácil interpretação é muito utilizado em sistemas de previsão de valores como vendas por exemplo, ou quaisquer outro cujo o percentual seja mais interpretável que os valores absolutos. Por exemplo, um vendedor dizer ao seu gerente que "aumentei $20 \%$ em minhas vendas" é mais intuitivo que "aumentei em $\$ 1000$ em minhas vendas" se o gerente verifica no quadro geral atingimento do percentual de meta de cada vendedor. A equação (2) descreve a fórmula para o MAPE onde $A_{t}$ é o valor esperado, $F_{t}$ é o valor previsto, $n$ é o número de amostras. A multiplicação por 100 converte o valor do erro em porcentagem.

$$
M A P E=\frac{1}{n} \sum_{t=1}^{n}\left|\frac{A_{t}-F_{t}}{A_{t}}\right|
$$

\section{Mean Squared Error (MSE)}

Erro Médio ao Quadrado (MSE) calcula a média dos erros do modelo ao quadrado, ou seja, a diferença quadrática média entre os valores reais e previstos. Penaliza valores muito distantes da média, onde diferenças menores ganham menos importância enquanto diferenças maiores recebem mais peso.

A equação (3) descreve a fórmula para o MSE onde $Y_{i}$ é o valor esperado, ${ }^{\wedge} Y_{i}$ é o valor previsto, elevados ao quadrado e $n$ é o número de amostras. A multiplicação por 100 converte o valor do erro em porcentagem.

$$
\mathrm{MSE}=\frac{1}{N} \sum_{i=1}^{N}\left(y_{i}-\hat{y}_{i}\right)^{2}
$$

\section{RESULTADOS E ANÁLISES}

Nesta seção serão apresentados os resultados obtidos na análise exploratória de dados (AED) e da aplicação do algoritmo de predição MLP. 


\subsection{Resultados da AED}

Na Figura 5 observa-se o comportamento do Total de Valores Sacados (Total amount Withdrawn) ao longo do intervalo de anos que se compõe todo conjunto de dados (2013 a 2017), que é a variável alvo a ser predita, neste estudo.

Figura 2. Variação do Total de Valores Sacados Anos

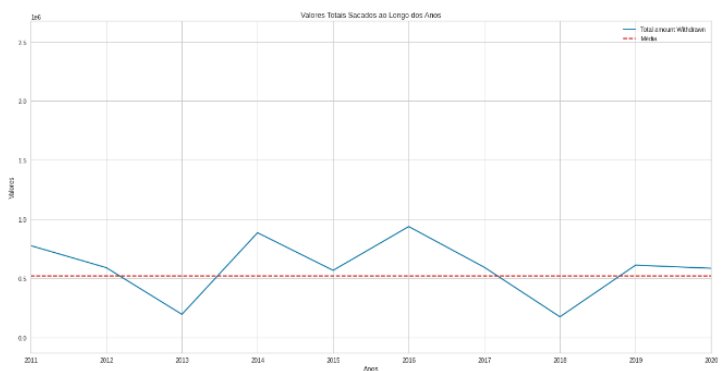

Nos anos de 2013 e 2017 ocorrem quedas significativas bem abaixo da linha da média, seguidas de recuperações que se mantém acima da média nos respectivos anos subsequentes. 0 que demonstra um padrão nas sazonalidades de alguma natureza de quedas e recuperações sempre ultrapassando a média.

O histograma representado na Figura 6 apresenta uma distorção à direita, que significa em estatística uma Inclinação ou Assimetria Positiva, que neste caso indica baixa frequência de saques de altos valores no período de 2013 a 2017.

Figura 3. Histograma - Total de Valores Sacados

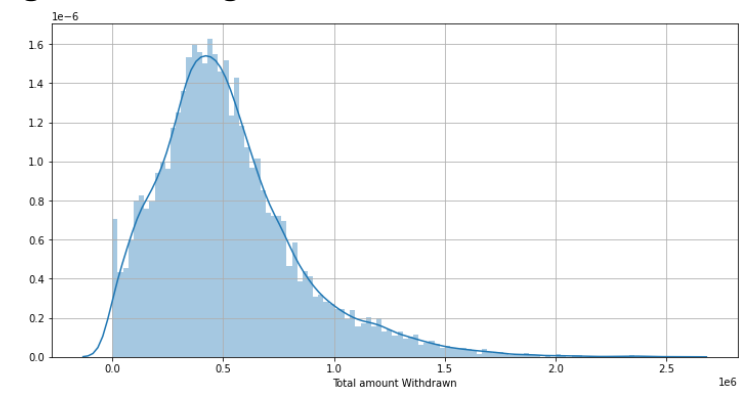

No gráfico de dispersão representado na Figura 7 observa-se o comportamento das movimentações dos ATMs listados no conjunto de dados consideração o No. Of Withdrawals (número de saques) e o Total amount Withdrawn (total sacado) por ATM.
Figura 4. Gráfico de Dispersão - Movimentação dos ATMs.

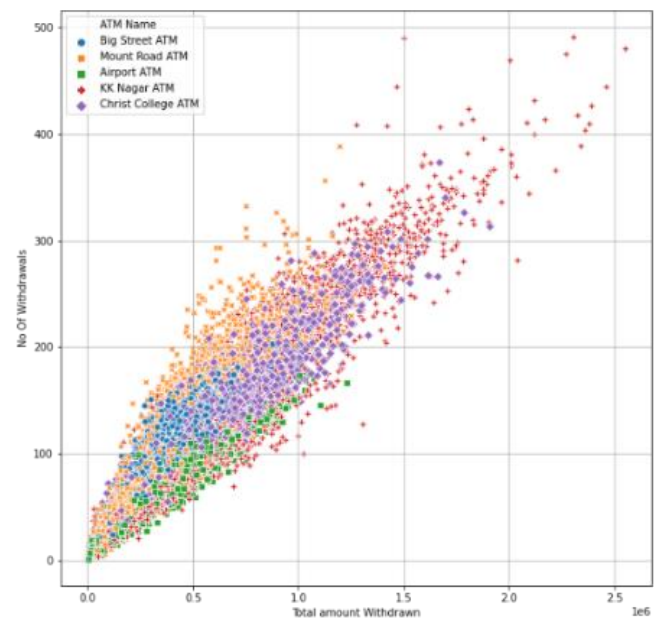

É possível observar um destaque significativo do KK Nagar (pontos vermelhos) que aponta uma maior incidência de número de saques e totais sacados sobre os demais ATMs e em contrapartida o Airport ATM (pontos verdes) que se destaque pelos menores números dentre a relação.

\subsection{Resultados do Algoritmo}

0 conjunto de dados (dataset) apresentado na seção 2.1 possui informações de movimentações de um período de 6 anos e 9 meses. Foram utilizados $80 \%$ da base para treinamento e $20 \%$ restante para testes. O experimento foi executado para dois ATMs chamados KK Nagar ATM e Christ College ATM.

Os gráficos servirão para uma análise visual dos resultados, eles comparam os valores reais (linha azul) com os valores preditos (linha laranja) pela MLP.

Na Figura 8 estão representados os resultados da previsão para o KK Nagar ATM.

Figura 5. Comparação entre Real e Predito - KK Nagar ATM.

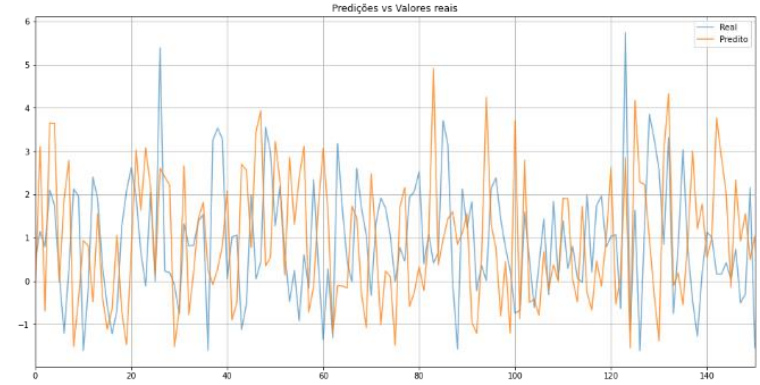

$\mathrm{Na}$ Figura 9 estão representados os resultados da previsão para Christ College ATM. 
Figura 9. Comparação entre Real e Predito Christ College ATM.

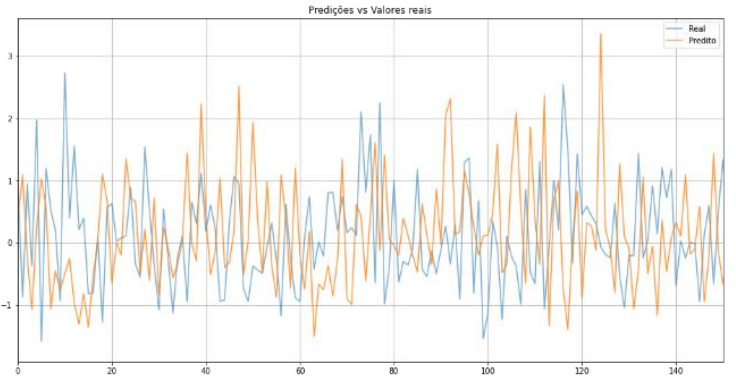

\subsection{Avaliação da Predição}

Os métodos de avaliação utilizados foram o Erro Percentual Absoluto (MAPE) descrito na seção 3.6.1 e o Erro Quadrático Médio (MSE) descrito na seção 3.6.2.

A tabela 5 compara os resultados obtidos com MAPE (Erro Percentual Absoluto Médio) dos ATMs KK Nagar ATM e Christ College ATM.

Tabela 5. Resultados do Mean Square Absolute Percentage

\begin{tabular}{cc}
\hline ATM & MAPE \\
\hline KK Nagar ATM & $35,262 \%$ \\
Christ College ATM & $23,122 \%$ \\
\hline
\end{tabular}

A tabela 6 compara os resultados obtidos com MAPE dos ATMs KK Nagar ATM e Christ College ATM.

Tabela 6. Resultados do Mean Squared Error.

\begin{tabular}{cc}
\hline ATM & MSE \\
\hline KK Nagar ATM & $22,8 \%$ \\
Christ College ATM & $16,9 \%$ \\
\hline
\end{tabular}

\section{CONCLUSÕES}

\subsection{Considerações}

Este estudo teve como objetivo principal a construção de um algoritmo de rede neural artificial do tipo FeedForward Multilayer Perceptron backpropagation, para fornecer uma previsão de reposição de numerários para ATM.

Com base na análise dos resultados, observou-se que o algoritmo conduziu um desempenho satisfatório com os dados do ATM Christ College apresentando um MAPE de 23\%. Com os dados do KK Nagar ATM O MAPE o resultado apresentou-se um pouco maior, em $35 \%$.

Para fins comparativos, foi também calculado o MSE sendo 16,9\% Christ College_ATM e 22,8\% para KK Nagar ATM respectivamente.

O gerenciamento eficiente dos ATMs, podem reduzir os custos financeiros por meio da otimização do gerenciamento de estoque de numerários, melhorar sua mobilização, reduzir perdas relacionadas a roubos e problemas de atendimento ao cliente entre outas situações onde um sistema inteligente de previsão torna-se crucial para prever com precisão a demanda de numerários para redes de ATMs.

Com isso pode-se concluir que as abordagens de tratamento de dados e a RNA experimentada foram capazes de desempenhar satisfatoriamente sobre o conjunto de dados, apresentando uma variação significativa para grupos diferentes de ATMs e considerando historicamente os valores de saques tendem sempre a estar distante da média.

\subsection{Trabalhos Futuros}

Alguns possíveis trabalhos futuros são:

- Aplicar o método MinMaxScaler para normalização dos dados.

- Variar com mais ênfase os parâmetros fornecidos pela biblioteca scikit-learn.

- Usar o método Leave One Out presente na bibliotecas scikit-learn através da classe (.LeaveOneOut) para separação de amostragem dos conjuntos de treino e testes.

- Implementar o modelo para mesmo problema utilizando a biblioteca TensorFlow.

\section{REFERÊNCIAS}

ARORA, N.; SAINI, J. R. Approximating Methodology: Managing Cash in Automated Teller Machines using Fuzzy ARTMAP Network. International Journal of Enhanced Research in Science Technology and Engineering, v.13, p. 318326, 2014.

ATM Marketplace. Global ATM installed base to reach 4M by 2021. Disponível em: https://www.atmmarketplace.com/news/globalatm-installed-base-to-reach-4m-by-2021/. Acesso em: 17 jun. 2020.

BRAGA, A. A.; CARVALHO, A. C. P. L. F.; LUDERMINR, T. B. Redes neurais artificiais: teoria e aplicações. 2. ed. Rio de Janeiro: LTC, 2007.

COUTINHO, E. et al. Utilização de Técnicas de Inteligência Computacional me Predição de Dados Meteorológicos. Seropédica: Revista 
Brasileira de Meteorologia, v. 31, n. 1, p. 24-36, 2016. https://doi.org/10.1590/0102-

$\underline{778620140115}$

DEEP LEARNING BOOK. O Neurônio, Biológico e

Matemático. Disponível em:

http://www.deeplearningbook.com.br/o-

neuronio-biologico-e-matematico. Acesso em: 22 jun. 2020.

DEEP LEARNING BOOK. Definindo o Tamanho do Mini-Batch. Disponível em: https://deeplearningbook.com.br/definindo-otamanho-do-mini-batch/. Acessado em: 19 jun. 2020.

KAGGLE INC. Competitions. Disponível em: https://www.kaggle.com/competitions. Acesso em: 17 jun. 2020.

KAGGLE. Data of ATM transactions of XYZ bank. Disponível em: https://www.kaggle.com/nitsbat/data-of-atmtransaction-of-xyz-bank. Acesso em: 10 abr. 2019.

LEONOV, P. et al. The use of artificial intelligence technology in the process of creating an ATM service model. Procedia Computer Science, v. 169, p. 203-208, 2020. https://doi.org/10.1016/j.procs.2020.02.137

MELO, G. S. Aplicação de aprendizado de máquina para previsão de fluxo de caixa em ATMs. 2018. Monografia (Bacharel em Engenharia da Computação) - Universidade Federal de Pernambuco, Recife, 2018.

PAIVA, R. C. Modelo de previsão e reposição de numerários em uma rede de caixas eletrônicos. 2006. Trabalho de Conclusão do Curso (Engenharia de Produção) - Escola Politécnica da Universidade de São Paulo, São Paulo, 2006. 